\title{
PARN-like Proteins Regulate Gene Expression in Land Plant Mitochondria by Modulating mRNA Polyadenylation
}

\author{
Takashi Hirayama
}

check for

updates

Citation: Hirayama, T. PARN-like Proteins Regulate Gene Expression in Land Plant Mitochondria by Modulating mRNA Polyadenylation. Int. J. Mol. Sci. 2021, 22, 10776. https://doi.org/10.3390/ ijms221910776

Academic Editor: Mamoru Sugita

Received: 30 August 2021

Accepted: 2 October 2021

Published: 5 October 2021

Publisher's Note: MDPI stays neutral with regard to jurisdictional claims in published maps and institutional affiliations.

Copyright: (c) 2021 by the author. Licensee MDPI, Basel, Switzerland. This article is an open access article distributed under the terms and conditions of the Creative Commons Attribution (CC BY) license (https:/ / creativecommons.org/licenses/by/ $4.0 /)$.
Institute of Plant Science and Resources, Okayama University, 2-20-1 Chuo, Kurahiki 710-0046, Okayama, Japan; hira-t@okayama-u.ac.jp

\begin{abstract}
Mitochondria have their own double-stranded DNA genomes and systems to regulate transcription, mRNA processing, and translation. These systems differ from those operating in the host cell, and among eukaryotes. In recent decades, studies have revealed several plant-specific features of mitochondrial gene regulation. The polyadenylation status of mRNA is critical for its stability and translation in mitochondria. In this short review, I focus on recent advances in understanding the mechanisms regulating mRNA polyadenylation in plant mitochondria, including the role of poly(A)-specific ribonuclease-like proteins (PARNs). Accumulating evidence suggests that plant mitochondria have unique regulatory systems for mRNA poly(A) status and that PARNs play pivotal roles in these systems.
\end{abstract}

Keywords: mitochondria; polyadenylation; poly(A)-specific ribonuclease

\section{Introduction: Overall View of Mitochondrial Transcription}

Mitochondria carry out oxidative phosphorylation (respiration) and various metabolic processes. The mitochondrion has its own DNA genome containing a small set of genes encoding proteins required for mitochondrial function. Mitochondria are involved not only in energy and metabolite production but also in diverse cellular processes, such as apoptosis and responses to stress [1,2]. Mitochondrial dysfunction in humans causes neurological disorders, suggesting this organelle has important roles in neuronal cell activity [3-5].

As mitochondria are found in almost all eukaryotes, where they play common roles in energy production and metabolite biosynthesis, it was previously thought that mitochondria in all eukaryotes tend to be the same. However, many features of these organelles are different in different species. For example, their genome structure and the number and organization of protein-coding genes vary [6], including among plants [7]. The different mitochondrial genome sizes reflect different gene organizations and different gene regulatory mechanisms as well. Proteomic analyses revealed that many proteins are required for mitochondrial function: nearly 1000 proteins are present in mitochondria [8,9]. The mitochondrial genome encodes $10-60$ proteins, while the nuclear genome encodes most mitochondrial proteins, which are imported into mitochondria following their translation in the cytoplasm [10]. Most mitochondrially targeted proteins encoded in the nuclear genome function in large protein complexes with proteins encoded in the mitochondrial genome. To preserve the stoichiometry of these complexes, finely tuned mechanisms balance the levels of proteins produced in the mitochondria vs. the cytoplasm. Thus, mitochondrial and cellular systems communicate with and regulate each other. Uncovering the systems that regulate gene expression in mitochondria is therefore important for understanding mitochondrial function and the relationships between organellar and cellular activities. Mitochondria and the nucleus have presumably established two-way communication to regulate each other's gene expression. One such form of communication is mitochondriato-nucleus signaling, which is also referred to as retrograde signaling [11-13]. Studies over the past decade have suggested that reactive oxygen species, ATP, Ca ions, peptides, and 
metabolites function as signaling molecules for this type of communication in both animals and plants [14-16].

Regulation of gene expression, including that of genes in both the nucleus and the mitochondria, primarily involves regulation of transcription initiation, translation, or stability of transcripts or proteins. Regulation of the initiation of mitochondrial gene transcription is believed to be largely dependent on the expression of the nucleus-encoded mitochondrial RNA polymerase, which is similar to T3 or T7 bacteriophage RNA polymerase. In human mitochondria, the RNA polymerase POLRMT is recruited to two transcription initiation sites, HSP and LSP, by the transcription factors TFAM and TFB2M, which bind to these sites [17-19]. These long polycistronic primary transcripts undergo maturation, in which protein-coding sequences and tRNAs are excised by several RNA endonucleases. In contrast to transcription in humans, transcription in plant mitochondria begins at multiple sites [20]. In Arabidopsis thaliana, transcription initiation occurs in at least 30 sites by two mitochondrial phage-type RNA polymerases, RpoTm and RpoTmp [21,22] (Figure 1). The resulting transcripts are translated independently and have different translation efficiencies [23]. Another unique feature of plant mitochondrial mRNAs is that their nucleotide sequences are edited considerably after transcription. In Arabidopsis, cytosine is converted to uracil at more than 400 sites $[24,25]$. The RNA editing status of mRNA does not affect its translation efficiency [23], suggesting that translation and RNA editing occur independently of each other.

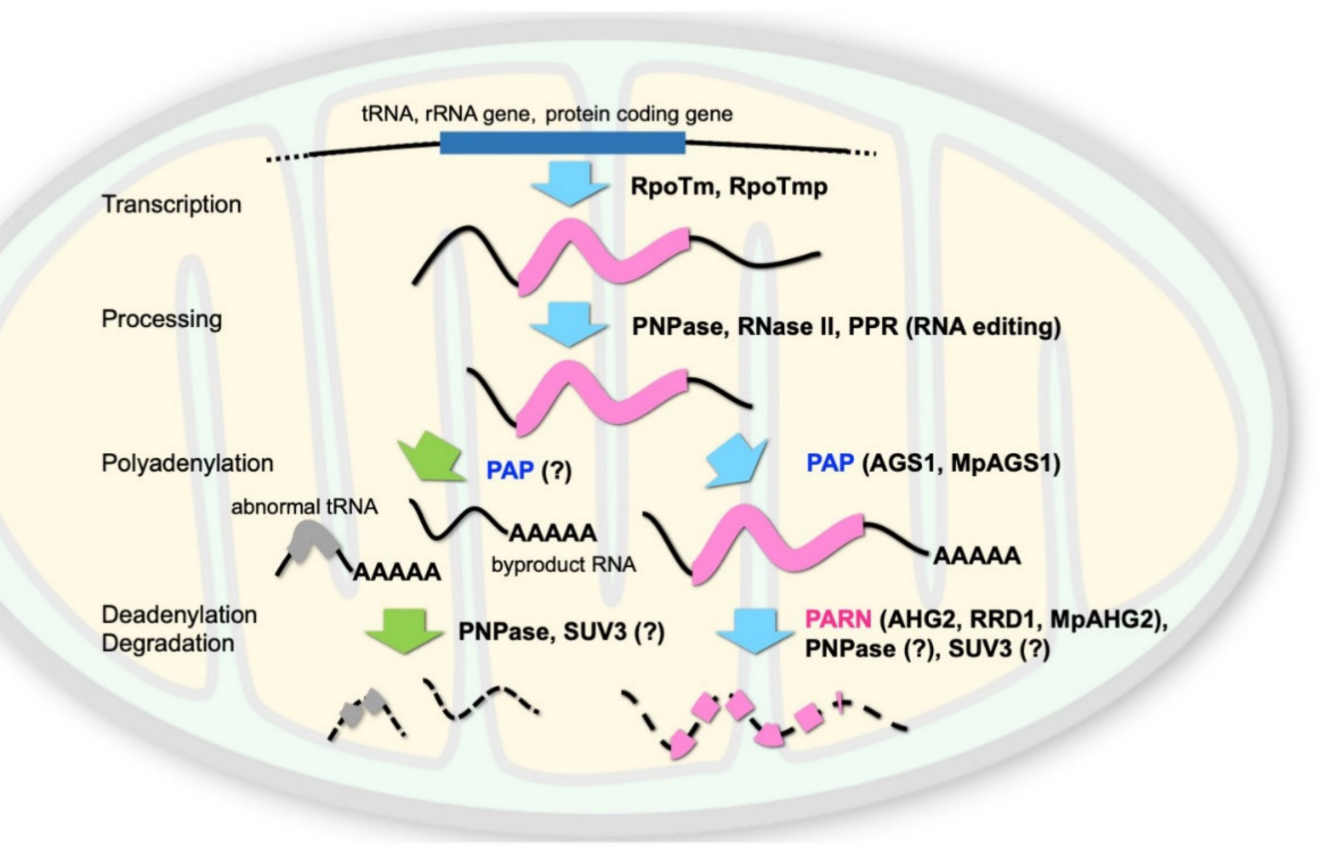

Figure 1. Cont. 


\begin{tabular}{|c|c|c|c|c|c|}
\hline Name & Function & Species & Gene ID & Description & References \\
\hline AtmtPNPase & $\begin{array}{l}\text { processing, } \\
\text { deadenylation, } \\
\text { degradation }\end{array}$ & Arabidopsis thaliana & At5g14580 & $\begin{array}{l}\text { polynuleotide phosprylase localizes at mitochondria, identified by } \\
\text { sequence similarity. }\end{array}$ & {$[52,53,54]$} \\
\hline $\begin{array}{l}\text { AtmtRNasell/ } \\
\text { EMB2730/RNR1 }\end{array}$ & processing & Arabidopsis thaliana & At5g02250 & $\begin{array}{l}\text { RNase R/RNase II, identified by sequence similarity, and identified as } \\
\text { an embryonic lethal mutation. }\end{array}$ & {$[52,53,86,87]$} \\
\hline AGS1 & polyadenylation & Arabidopsis thaliana & At2g17580 & $\begin{array}{l}\text { bacterial type poly(A) polymerase localizes at mitochondria, Identified } \\
\text { as suppressor mutations for ahg2-1. }\end{array}$ & [74] \\
\hline MpAGS1 & polyadenylation & Marchantia polymorpha & $\begin{array}{l}\text { Mapoly0171s0002, } \\
\text { Mapoly0136s0037 }\end{array}$ & $\begin{array}{l}\text { bacterial type poly(A) polymerase localizes at mitochondria, identified } \\
\text { by sequence similarity. }\end{array}$ & [79] \\
\hline AHG2/AtPARN & deadenylation & Arabidopsis thaliana & At1g55870 & $\begin{array}{l}\text { poly(A) specific ribonuclease localizes at mitochondria, identified with } \\
\text { sequence similarity, and identified as an ABA hypersensitive } \\
\text { germination mutation (ahg2-1). }\end{array}$ & {$[63,68,72,74]$} \\
\hline RRD1 & deadenylation & Arabidopsis thaliana & At3g25430 & $\begin{array}{l}\text { poly(A) specific ribonuclease localizes at mitochondria, identified as a } \\
\text { temperature dependent root differentiation defective mutation. }\end{array}$ & {$[63,81]$} \\
\hline MPAHG2 & deadenylation & Marchantia polymorpha & Mapoly0076s0056 & $\begin{array}{l}\text { poly(A) specific ribonuclease localizes at mitochondria, identified by } \\
\text { sequence similarity. }\end{array}$ & [79] \\
\hline Ossuv3 & degradation & Oryza sativa & Os03g0746500 & $\begin{array}{l}\text { SUV3 like DExH-box RNA helicase gene, identified by sequence } \\
\text { similarity. }\end{array}$ & [56] \\
\hline AtSUV3/EDA15 & degradation & Arabidopsis thaliana & At4g14790 & $\begin{array}{l}\text { SUV3 like DExH-box RNA helicase gene, identified by sequence } \\
\text { similarity, and identified as an embryonic lethal mutation. }\end{array}$ & {$[55,52,88]$} \\
\hline
\end{tabular}

Figure 1. Processing of plant mitochondrial mRNAs. Upper panel: In land plant mitochondria, genes in the mitochondrial genome are transcribed separately by T3/T7 phage type RNA polymerases (RpoTm and RpoTmp) [26-28]. Primary transcripts of protein coding mRNAs are trimmed at their $5^{\prime}$ and $3^{\prime}$ ends by polynucleotide phosphorylase (PNPase) and RNase II $[26,27,29,30]$. Some mRNA is edited at specific residues by pentatricopeptide repeat proteins (PPRs). Unknown regulatory signals then induce polyadenylation at the $3^{\prime}$ ends of the mRNAs via a poly(A) polymerase (PAP) such as AHG2 SUPPRESSOR1 (AGS1) [31]. RNAs with abnormal structures are degraded by the mRNA quality surveillance machinery. Polyadenylated mRNA is believed to be degraded by RNase following its deadenylation by poly(A)-specific ribonucleases (PARNs) such as ABA-HYPERSENSITIVE GERMINATION2 (AHG2)/AtPARN [31-34] and ROOT REDIFFERENTIATION DEFECTIVE1 (RRD1) [32,35]. PNPase may participate in this process. MpAGS1 and MpAHG2 are Marchantia paralogs of Arabidopsis AGS1 and AHG2 [36], respectively. SUV3-like proteins may be involved in certain processes (right side) [26,37-39]. tRNAs (and rRNAs) with abnormal structures and byproducts of mRNA processing are also polyadenylated and degraded, presumably by PNPase and the SUV3-like protein complex, as observed in human mitochondria (left side). Lower panel: the information of the factors shown in the upper panel. ? mark means that the involvement of these factors have been suggested but not confirmed yet.

The stability of mRNA is one of the major factors determining the expression level of a gene; stable mRNA is translated more frequently than unstable mRNA. Therefore, the regulation of mRNA stability is important for the regulation of gene expression. In addition, this regulatory system plays a pivotal role in the quality control of mRNA [40-43]. The poly(A) tail attached to the $3^{\prime}$ end of the mRNA is deeply involved in the regulation of mRNA stability and translation efficiency. In eukaryotic cells, the poly(A) tail contributes to the stabilization of mRNA in the cytoplasm, but in prokaryotic cells, it functions as a degradation mark $[44,45]$. Since mitochondria are symbiotic organelles that are believed to have originated from Alphaproteobacteria, we may expect the poly $(\mathrm{A})$ tails of eukaryotic mitochondrial mRNAs to be regulated in a manner similar to that in bacteria. However, the situation is not as simple as the other mitochondrial characters as described above. Many excellent articles provide an overall view of mitochondrial RNA metabolism and its diversity [46-48]. Therefore, in this short review, I will focus on the regulation of the poly(A) tail in mitochondria and describe recent progress in elucidating the regulation and functions of poly $(\mathrm{A})$ tracts of plant mitochondrial mRNAs.

\section{Polyadenylation of Mitochondrial mRNAs: Regulation and Functions Differ across Species}

In human mitochondria, most mRNA is excised from primary long poly-cistronic transcripts and then polyadenylated at its $3^{\prime}$ end. This poly(A) addition is required for certain mRNAs possessing an open reading frame but lacking a stop codon; the addition of poly(A) to the $3^{\prime}$ end produces a stop codon, resulting in a functional complete open reading frame [49]. The detection of polyadenylated mRNA implies that poly(A) does not serve as a degradation mark in human mitochondria. Several reports indicate that polyadenylation increases mRNA stability in human mitochondria, such as cytoplasmic mRNA [50,51]. Conversely, several studies demonstrate no clear linkage between the poly(A) status and 
stability of mitochondrial mRNA $[52,53]$. The polyadenylation of tRNAs with abnormal structures and of truncated mRNAs contributes to their rapid degradation [54,55].

The polyadenylation of mitochondrial mRNA has not been detected in budding yeast (Saccharomyces cerevisiae) [56], but a dodecamer sequence (5'-AAUAA(U/C)AUUCUU-3') is present at the $3^{\prime}$ untranslated region of mitochondrial mRNA in this organism [57]. This dodecamer sequence stabilizes mRNA, presumably by associating with specific RNA binding proteins [58]. By contrast, in plant mitochondria, polyadenylation of mitochondrial mRNAs is thought to act as a degradation mark, as observed in bacteria $[47,59]$. Therefore, polyadenylation of plant mitochondrial mRNAs is usually not detectable under normal conditions. As described below, however, polyadenylated mitochondrial mRNAs have been observed in mutants defective in RNA processing or RNA metabolism.

\section{Factors Possibly Regulating the Poly(A) Status of Mitochondrial mRNAs in Plants}

Regulation of poly(A) status requires both polyadenylation and deadenylation processes. In human mitochondria, mitochondria-specific poly(A) polymerase (mtPAP) is a key factor in the addition of a poly(A) tail $[52,60]$. Similar to the mechanism found in bacteria [61], polynucleotide phosphorylase (PNPase), which possesses both $3^{\prime}-5^{\prime}$ exoribonuclease and RNA polymerase activities, plays a critical role in the deadenylation of human mitochondrial mRNA [60]. Human PNPase partakes in the mRNA degradation associated with Suv3 RNA helicase (hSuv3) in mitochondria [62,63]. The PPR-containing protein LRPPRC stabilizes mitochondrial mRNA by inhibiting PNPase activity and promoting mtPAP activity in mitochondria [64]. In the plastids of plants, PNPase plays a pivotal role in poly(A)-assisted mRNA degradation [65].

Arabidopsis possesses the mitochondrially targeted PNPase AtmtPNPase. Therefore, it is possible that PNPase is key factor in poly(A) removal and RNA degradation in plant mitochondria. Moreover, downregulation of AtmtPNPase results in the accumulation of unprocessed polyadenylated mitochondrial mRNAs [26-28], suggesting that AtmtPNPase functions in mRNA processing, including regulation of the poly(A) status of mitochondrial mRNA (Figure 1). In addition, in the AtmtPNPase knockdown line, polyadenylated mitochondrial rRNA and tRNA are detected $[27,28]$, suggesting that PNPase is involved in the degradation of polyadenylated forms of these RNAs. This finding is reminiscent of tRNA quality control in human mitochondria, where tRNA possessing an abnormal structure is polyadenylated and degraded by the PNPase-Suv3 complex [54,55]. SUV3-like genes encoding proteins with RNA helicase activity are found in plant genomes $[37,38]$ and are thought to function in RNA degradation in mitochondria. Taken together, these observations suggest that a system analogous to that found in humans regulates the poly(A) status in plant mitochondria, at least for rRNA, tRNA, and their byproducts during mRNA processing. Conversely, the effects of polyadenylation on mRNA stability differ between humans and plants, suggesting that plants employ distinct systems to regulate the poly(A) status of mitochondrial mRNA. Forward genetic studies analyzing hormonal responses or developmental processes in Arabidopsis revealed that poly(A)-specific ribonuclease (PARN), which regulates the poly(A) status of cytoplasmic mRNA, plays a key role in regulating the poly(A) status of mitochondrial mRNA in plants.

\section{Poly(A) Removal Machinery of Eukaryotes}

Eukaryotes possess various poly(A) removal enzymes that are thought to regulate the poly(A) status of cytoplasmic mRNA. The CCR4-NOT complex is the major poly(A) removal enzyme for cytoplasmic mRNA; its activity leads to the degradation of mRNA. The PAN2-PAN3 complex is predicted to shorten the poly(A) stretch, thereby destabilizing RNA-protein complexes composed of poly(A) tails and poly(A)-binding proteins $[66,67]$. The third poly(A) removal enzyme is PARN. This deadenylase was first purified from HeLa cells, and the gene encoding its activity was identified using Xenopus oocytes [68,69]. Homologous genes have since been identified in various eukaryotes. However, budding yeast and fruit fly (Drosophila melanogaster) do not possess PARN-related genes [70]. In addition, 
the PARN genes of nematode (Caenorhabditis elegans) and fission yeast (Schizosaccharomyces pombe) are dispensable, implying that PARN does not have a conserved, essential function in eukaryotic cells [32,71]. PARN is involved in the maturation of the RNA component of telomerase, ribosomal RNA, and miRNA in mammalian cells [72-75], suggesting that PARNs have specialized functions in different organisms. The first plant PARN gene to be isolated was Arabidopsis AtPARN [32,33]. Null mutations of this gene result in embryonic lethality, suggesting that AtPARN plays essential roles in Arabidopsis. AtPARN is also implicated in the response of Arabidopsis to an elicitor released by an infectious fungus, presumably by regulating the production of proteins required for defense responses [76]. These findings suggest that the cellular functions of PARNs have diverged in plants, fungi, and animals.

\section{Arabidopsis PARN Regulates the Poly(A) Status of Mitochondrial mRNAs}

The Arabidopsis genome contains genes encoding the CCR4-NOT complex [77,78], presumably a major poly(A) removal factor in the cytoplasm. Thus, the lethality of the null AtPARN mutants indicates that AtPARN targets specific RNAs whose deadenylation is crucial for their function. Studies of AtPARN have been facilitated by the identification of a weak mutant allele, the $A B A$ hypersensitive germination 2-1 (ahg2-1) mutant, which shows elevated endogenous abscisic acid (ABA) and salicylic acid levels and increased sensitivity to ABA treatment [34,79]. The ahg2-1 mutant harbors a 5-bp deletion in the coding region of the PARN gene that causes a frameshift. However, alternative splicing partially compensates for this mutation, resulting in the reduced production of full-length PARN with a four-amino acid substitution in a non-conserved region [34]. Many mutants defective in cytoplasmic mRNA metabolism exhibit ABA-related phenotypes [31]. Therefore, regarding the ABA hypersensitive phenotype of ahg2-1, the function of AHG2/AtPARN was not explored further until the identification of the target RNAs of AHG2/AtPARN.

Transcriptome analysis of the ahg 2-1 mutant followed by a poly(A) assay of transcripts revealed that the targets of AHG2/AtPARN are mitochondrial mRNAs [80]. Polyadenylated mitochondrial mRNA is usually barely detectable in wild-type plants, but it accumulates in ahg2-1. In addition, most of the suppressor mutants isolated for ahg2-1 (ahg2 suppressor, ags mutants) possess mutant alleles of AGS1, encoding a mitochondria-localized bacterial-type PAP [80]. The ags1 mutations suppress the lethality of the null AHG2/AtPARN mutation. Genetic analysis showed that the balance between the PAP activity of AGS1 and the deadenylase activity of AHG2/AtPARN is important for mitochondrial function. The mitochondrial localizations of AHG2/PARN and AGS1 were confirmed using transgenic plants expressing GFP fusion proteins [80] and were partially supported by proteomic analysis of the Arabidopsis mitochondrial ribosome [81]. In contrast to AHG2/AtPARN, loss-of-function mutants of AGS1 do not have any visible phenotypes, implying that poly(A) addition to mitochondrial mRNAs is not essential for plants.

These observations, which contradicted previous findings, prompted the question of whether the mitochondrial function of PARN detected in Arabidopsis is conserved among plants. Comparison of the amino acid sequences of putative PARNs among eukaryotes showed that most plant paralogs contain N-terminal extension sequences predicted to function as mitochondrial signaling sequences [82]. Therefore, plant PARNs likely function in mitochondria.

\section{The AHG2/AtPARN-AGS1 Regulatory System Is Conserved in Liverwort}

Paralogs of AHG2/AtPARN and AGS1 in the liverwort Marchantia polymorpha, a member of a basal land plant lineage [83], were recently analyzed in detail [36]. M. polymorpha contains one AHG2/AtPARN homolog, MpAHG2, and one AGS1 homolog, MpAGS1. GFP fusion proteins of MpAHG2 and MpAGS1 localize to the mitochondria in Marchantia, and a recombinant MpAHG2 protein exhibits deadenylase activity in in vitro assays using artificial mRNA substrates. Disruptive mutations of MpAHG2 cause lethality, but mutations of MpAGS1 do not affect the growth of Marchantia. A loss-of-function mutation of 
MpAGS1 suppresses the lethality of MpAHG2 disruption, which is reminiscent of the relationship between the ahg2 mutation and the ags1 mutation in Arabidopsis. Weak alleles of Mpahg2 harboring mutations in an intron show increased accumulation of polyadenylated mitochondrial mRNAs. Transgenic Marchantia strongly expressing MpAGS1 accumulate polyadenylated mitochondrial mRNA even though recombinant MpAGS1 protein show no poly(A) polymerase activity in vitro [36]. These observations strongly suggest that the regulation of mitochondrial mRNA polyadenylation status by PARN and PAP is conserved in Arabidopsis and Marchantia and that this regulatory system is likely conserved at least among land plants (Figure 1).

\section{Another PARN-Like Arabidopsis Protein Also Functions in Mitochondria}

Arabidopsis contains an additional PARN-like gene, At3g25430. However, the predicted product of this gene lacks several conserved motifs commonly found in PARNs in various eukaryotes. In addition, the loss-of-function mutation of this gene confers no visible phenotype [32]. Therefore, until recently, it was thought that At3g25430 does not encode a functional PARN. However, a recent molecular genetic study shed light on the importance of this gene for mitochondrial function and root development. Otsuka and collaborators analyzed several temperature-dependent Arabidopsis mutants defective in lateral root morphogenesis [35,84]. Among these, the root redifferentiation defective 1 (rrd1) mutant has a nonsense mutation in the coding region of At3g25430. The RRD1-GFP fusion protein localized to the mitochondria. In addition, polyadenylated mitochondrial mRNA accumulated in the rrd1 mutant, suggesting that, similar to AHG2/AtPARN, RRD1 plays a substantial role in removing poly(A) from mitochondrial mRNA. This idea is further supported by the observation that the ags1 mutation suppresses the $r r d 1$ phenotype [35].

Other $r r d$ mutants ( $r r d 2$ and $r r d 4$ ) were isolated by this group using the same screening procedures [35]. These two mutants are defective in pentatricopeptide repeat proteins (PPRs). Plants contain many genes encoding PPRs, and a group of PPRs is involved in RNA editing of mitochondrial mRNAs. RRD2 and RRD4 localize to the mitochondria and are required for the editing of several mRNAs, such as $c c b 2$ and atp 4 mRNA, respectively [35]. The authors suggested that reactive oxygen species produced by deteriorated mitochondria could be the major factor leading to abnormal root morphogenesis. These observations strongly suggest that proper mitochondrial RNA metabolism, which is necessary for normal mitochondrial function, ensures proper root development required for plant growth.

\section{AHG2/AtPARN and RRD1 Appear to Have Distinct Physiological Functions}

AHG2/AtPARN and RRD1 share many characteristics, including amino acid sequences, mitochondrial localization, and mutant phenotypes, such as the accumulation of polyadenylated mitochondrial mRNAs and genetic interactions with ags1. By contrast, as described above, null mutations of AHG2/AtPARN are lethal, suggesting that AHG2/AtPARN and RRD1 have distinct functions. This idea is supported by the different effects of $a h g 2-1$ and $r r d 1$ on the stability of mitochondrial complexes [35,80]. RRD1 co-immunoprecipitates with an AHG2-GFP fusion protein expressed in transgenic Arabidopsis plants (Hirayama, unpublished results). Since human PARN forms an active homodimer, AHG2/AtPARN and RRD1 are expected to form a heterodimer. However, yeast two-hybrid experiments failed to reveal direct physical interactions between these proteins in yeast cells (Hirayama, unpublished results), suggesting that AHG2/AtPARNRRD1 heterodimer formation may require additional components. Alternatively, perhaps AHG2/AtPARN and RRD1 are components of a large multi-protein complex involved in mitochondrial mRNA processing or degradation. It is also possible that AHG2/AtPARN and RRD1 have different target preferences and distinct functions because their effects on the stability of respiratory complexes are different $[35,80]$. Further analyses should clarify the relationship between AHG2/AtPARN and RRD1. 


\section{Physiological Role of the Polyadenylation of Plant Mitochondrial mRNA}

Defects in PARN-like genes in Arabidopsis and Marchantia lead to the accumulation of polyadenylated mitochondrial mRNA, which is barely detectable in wild-type plants. Null mutations of Arabidopsis AHG2 / AtPARN and Marchantia PARN are lethal but are suppressed by defects in $A G S 1$ or MpAGS1, respectively. These findings suggest that the removal of poly(A) from mitochondrial mRNA by PARN is essential for plant mitochondria. Moreover, they are consistent with the idea that polyadenylation of the $3^{\prime}$ end of mRNA functions as a degradation mark in plant mitochondria as part of an mRNA quality and/or quantity control mechanism.

If this is the case, polyadenylation of mitochondrial mRNA should be tightly regulated. However, null mutants of $A G S 1$ and MpAGS1 are viable and grow almost normally [36,80]. We cannot completely rule out the possibility that other polyadenylation factors compensate for these PAP mutations. However, it is plausible that these PAPs are major poly(A) polymerases because null mutations of these enzymes can suppress PARN mutations, including null mutations. If polyadenylation is involved in the quality control of mitochondrial mRNA, the polyadenylated mRNAs would likely have abnormal sequences or structures. In the case of $a h g 2-1$, however, there are no abnormalities in the sequences, including RNA editing sites, of polyadenylated mRNAs [80]. Therefore, it is not clear whether polyadenylation of mRNA is essential for plant mitochondrial function or whether it is involved in the quality control of mRNA.

PNPase plays important roles in the maturation and/or degradation of mitochondrial mRNA in plants. Null mutations of AtmtPNPase results in lethality, and the downregulation of this gene leads to polyadenylation of mitochondrial mRNAs at multiple sites [26-28]. Thus, findings about the poly(A) status of plant mitochondrial mRNA raise questions about the relationship between PARN and mitochondrial PNPase. The molecular phenotypes of ahg2-1 and the AtmtPNPase knockdown line are similar: both lines accumulate polyadenylated mitochondrial mRNA. However, the polyadenylation sites detected in the AtmtPNPase knockdown line are diverse and different from those reported for transcript ends, suggesting that processing at the $3^{\prime}$ end of mRNA is compromised in this line [26-28]. By contrast, ahg2-1 is affected only in the length of poly(A) and not in its position at the $3^{\prime}$ end of mRNA, implying that PNPase is involved in mRNA processing rather than poly(A) regulation in plant mitochondria $[80,85]$ (Figure 1). Mitochondrial mRNA is thought to be degraded after poly(A) removal. However, no information is available about the RNase responsible for this process. PNPase may function in this process in plants, such as in mammalian cells.

Another important question is how PARNs and PAPs in mitochondria are regulated. The expression levels of these genes do not differ among tissues and are not affected by external stimuli, such as hormone treatments or environmental stress. Thus, PARNs and PAPs must be regulated at the post-transcriptional or post-translational level. In mammalian cells, the Pi/ATP ratio in the mitochondrial matrix regulates the poly(A) status of mitochondrial mRNA and the translation efficiency of mitochondrial proteins, which in turn alters the ATP biosynthetic activity of mitochondria [63]. A similar situation may occur in plant mitochondria; namely, polyadenylation of mRNA may regulate translation efficiency. The abnormal protein accumulation observed in ahg2-1 and $r r d 1$ seems to be consistent, at least in part, with this idea [35,80]. Regarding the regulation of PARNs and AGS1s, the poly(A) removal activities of AHG2/AtPARN and RRD1 cannot be detected in an in vitro assay, whereas that of MpAHG2 is observed in the same assay. Conversely, the poly(A) polymerase activity of AtAGS1 is detected in vitro, while that of MpAGS1 is undetectable in the same assay $[35,36,80]$. These results suggest that other factors are required for the activities of AHG2/AtPARN, RRD1, and MpAGS1. PNPase is a good candidate for such a factor based on its predicted activity, but there is currently no direct evidence supporting this idea. Identifying such factors will shed light on the regulatory system of PARNs and PAPs in plant mitochondria and offer clues about the physiological roles of the polyadenylation and deadenylation of mitochondrial mRNAs in plants. 
Finally, it is curious that land plants came to use PARN for the regulation of mitochondrial mRNA metabolism. PARNs in animals function in the cytoplasm (including p-bodies), not in mitochondria. Presumably, during the establishment of symbiotic organelles, the forms and functions of mitochondria highly diverged as they adapted to the environment of the host cell $[86,87]$. There are many differences between animal and plant cells, but when examining organellar gene expression, the existence of another symbiotic organelle, plastids, cannot be ignored. It appears that mitochondria and plastids were acquired separately by ancestral plant cells When plastids were becoming integrated as symbiotic organelles in the host cells, the cells needed to establish distinct regulatory systems for mitochondria and plastids. It is possible that the plant cells diverted the function of PARN from a cytoplasmic mRNA regulator into a mitochondrial one. Under this scenario, lineages possessing plastids would use PARN as the regulator of the poly(A) region of mitochondrial mRNA. However, Chlamydomonas, a unicellular photosynthetic alga, does not contain genes homologous to PARNs and possesses distinct regulatory systems for mitochondrial RNA metabolism in which mitochondrial mRNA is polycytidylated [88]. Further information is needed to understand the discrepancy in the utilization of PARNs among eukaryotes. Meanwhile, the roles of PARNs in plant mitochondria should be further established.

\section{Concluding Remarks and Future Prospects}

Accumulating evidence suggests that land plants have developed a unique system for regulating the expression of mitochondrial genes by modulating the poly(A) status of mitochondrial mRNAs. PARN plays an important role in this system (Figure 1); by contrast, in mammalian cells, PARN functions in the cytosol. It is not currently clear why plants use PARN for mitochondrial mRNA regulation. However, PARN is essential for plants, indicating that this enzyme plays a crucial and unique role in plants. In addition to regulation of mRNA poly(A) status, plant mitochondria possess various unique features, such as larger mitochondrial genomes and extreme editing of mRNA. Since the mitochondrion is an important hub for stress responses in eukaryotes [1,2], further studies on the regulation of mitochondrial functions, including transcription and translation, will provide important insights into plant stress responses. The hidden secrets of PARN-dependent mitochondrial mRNA regulation will be uncovered in the near future, opening new avenues of plant mitochondrial research.

Funding: This work was supported by a Grant-in-Aid for Scientific Research by MEXT Japan (no. 21H02509).

Institutional Review Board Statement: Not applicable.

Informed Consent Statement: Not applicable.

Conflicts of Interest: The author declares no conflict of interest.

\section{References}

1. Galluzzi, L.; Kepp, O.; Kroemer, G. Mitochondria: Master Regulators of Danger Signalling. Nat. Rev. Mol. Cell Biol. 2012, 13, 780-788. [CrossRef]

2. Liberatore, K.L.; Dukowic-Schulze, S.; Miller, M.E.; Chen, C.; Kianian, S.F. The Role of Mitochondria in Plant Development and Stress Tolerance. Free Radic. Biol. Med. 2016, 100, 238-256. [CrossRef]

3. Mattson, M.P.; Gleichmann, M.; Cheng, A. Mitochondria in Neuroplasticity and Neurological Disorders. Neuron 2008, 60, 748-766. [CrossRef]

4. Su, B.; Wang, X.; Zheng, L.; Perry, G.; Smith, M.A.; Zhu, X. Abnormal Mitochondrial Dynamics and Neurodegenerative Diseases. Biochim. Biophys. Acta BBA-Mol. Basis Dis. 2010, 1802, 135-142. [CrossRef] [PubMed]

5. Russell, O.M.; Gorman, G.S.; Lightowlers, R.N.; Turnbull, D.M. Mitochondrial Diseases: Hope for the Future. Cell 2020, 181, 168-188. [CrossRef]

6. Morley, S.A.; Nielsen, B.L. Plant Mitochondrial DNA. Front. Biosci. Landmark Ed. 2017, 22, 1023-1032. [CrossRef] [PubMed]

7. Burger, G.; Gray, M.W.; Franz Lang, B. Mitochondrial Genomes: Anything Goes. Trends Genet. 2003, 19, 709-716. [CrossRef] [PubMed]

8. Rao, R.S.P.; Salvato, F.; Thal, B.; Eubel, H.; Thelen, J.J.; Møller, I.M. The Proteome of Higher Plant Mitochondria. Mitochondrion 2017, 33, 22-37. [CrossRef] [PubMed] 
9. Morgenstern, M.; Stiller, S.B.; Lübbert, P.; Peikert, C.D.; Dannenmaier, S.; Drepper, F.; Weill, U.; Höß, P.; Feuerstein, R.; Gebert, M.; et al. Definition of a High-Confidence Mitochondrial Proteome at Quantitative Scale. Cell Rep. 2017, 19, 2836-2852. [CrossRef] [PubMed]

10. Wasilewska, A.; Vlad, F.; Sirichandra, C.; Redko, Y.; Jammes, F.; Valon, C.; dit Frey, N.F.; Leung, J. An Update on Abscisic Acid Signaling in Plants and More... Mol. Plant 2008, 1, 198-217. [CrossRef]

11. Butow, R.A.; Avadhani, N.G. Mitochondrial Signaling: The Retrograde Response. Mol. Cell 2004, 14, 1-15. [CrossRef]

12. Liu, Z.; Butow, R.A. Mitochondrial Retrograde Signaling. Annu. Rev. Genet. 2006, 40, 159-185. [CrossRef]

13. Woodson, J.D.; Chory, J. Coordination of Gene Expression between Organellar and Nuclear Genomes. Nat. Rev. Genet. 2008, 9 , 383-395. [CrossRef]

14. Da Cunha, F.M.; Torelli, N.Q.; Kowaltowski, A.J. Mitochondrial Retrograde Signaling: Triggers, Pathways, and Outcomes. Oxid. Med. Cell. Longev. 2015, 2015, e482582. [CrossRef]

15. Møller, I.M. What Is Hot in Plant Mitochondria? Physiol. Plant. 2016, 157, 256-263. [CrossRef]

16. Kotiadis, V.N.; Duchen, M.R.; Osellame, L.D. Mitochondrial Quality Control and Communications with the Nucleus Are Important in Maintaining Mitochondrial Function and Cell Health. Biochim. Biophys. Acta BBA—Gen. Subj. 2014, 1840, 1254-1265. [CrossRef] [PubMed]

17. Posse, V.; Gustafsson, C.M. Human Mitochondrial Transcription Factor B2 Is Required for Promoter Melting during Initiation of Transcription*. J. Biol. Chem. 2017, 292, 2637-2645. [CrossRef]

18. Hillen, H.S.; Morozov, Y.I.; Sarfallah, A.; Temiakov, D.; Cramer, P. Structural Basis of Mitochondrial Transcription Initiation. Cell 2017, 171, 1072-1081.e10. [CrossRef]

19. Gustafsson, C.M.; Falkenberg, M.; Larsson, N.-G. Maintenance and Expression of Mammalian Mitochondrial DNA. Annu. Rev. Biochem. 2016, 85, 133-160. [CrossRef] [PubMed]

20. Kühn, K.; Weihe, A.; Börner, T. Multiple Promoters Are a Common Feature of Mitochondrial Genes in Arabidopsis. Nucleic Acids Res. 2005, 33, 337-346. [CrossRef] [PubMed]

21. Emanuel, C.; von Groll, U.; Müller, M.; Börner, T.; Weihe, A. Development- and Tissue-Specific Expression of the RpoT Gene Family of Arabidopsis Encoding Mitochondrial and Plastid RNA Polymerases. Planta 2006, 223, 998-1009. [CrossRef]

22. Kuhn, K.; Richter, U.; Meyer, E.H.; Delannoy, E.; Falcon de Longevialle, A.; O’Toole, N.; Borner, T.; Millar, A.H.; Small, I.D.; Whelan, J. Phage-Type RNA Polymerase RPOTmp Performs Gene-Specific Transcription in Mitochondria of Arabidopsis thaliana. Plant. Cell 2009, 21, 2762-2779. [CrossRef] [PubMed]

23. Planchard, N.; Bertin, P.; Quadrado, M.; Dargel-Graffin, C.; Hatin, I.; Namy, O.; Mireau, H. The Translational Landscape of Arabidopsis Mitochondria. Nucleic Acids Res. 2018, 46, 6218-6228. [CrossRef] [PubMed]

24. Giegé, P.; Brennicke, A. RNA Editing in Arabidopsis Mitochondria Effects $441 \mathrm{C}$ to U Changes in ORFs. Proc. Natl. Acad. Sci. USA 1999, 96, 15324-15329. [CrossRef]

25. Small, I.D.; Schallenberg-Rüdinger, M.; Takenaka, M.; Mireau, H.; Ostersetzer-Biran, O. Plant Organellar RNA Editing: What 30 Years of Research Has Revealed. Plant. J. 2020, 101, 1040-1056. [CrossRef] [PubMed]

26. Perrin, R.; Meyer, E.H.; Zaepfel, M.; Kim, Y.-J.; Mache, R.; Grienenberger, J.-M.; Gualberto, J.M.; Gagliardi, D. Two Exoribonucleases Act Sequentially to Process Mature 3'-Ends of Atp9 MRNAs in Arabidopsis Mitochondria. J. Biol. Chem. 2004, 279, 25440-25446. [CrossRef]

27. Perrin, R.; Lange, H.; Grienenberger, J.M.; Gagliardi, D. AtmtPNPase Is Required for Multiple Aspects of the 18S RRNA Metabolism in Arabidopsis thaliana Mitochondria. Nucleic Acids Res. 2004, 32, 5174-5182. [CrossRef]

28. Holec, S.; Lange, H.; Kuhn, K.; Alioua, M.; Borner, T.; Gagliardi, D. Relaxed Transcription in Arabidopsis Mitochondria Is Counterbalanced by RNA Stability Control Mediated by Polyadenylation and Polynucleotide Phosphorylase. Mol. Cell Biol. 2006, 26, 2869-2876. [CrossRef]

29. Bollenbach, T.J.; Lange, H.; Gutierrez, R.; Erhardt, M.; Stern, D.B.; Gagliardi, D. RNR1, a 3'-5' Exoribonuclease Belonging to the RNR Superfamily, Catalyzes 3' Maturation of Chloroplast Ribosomal RNAs in Arabidopsis thaliana. Nucleic Acids Res. 2005, 33, 2751-2763. [CrossRef]

30. Tzafrir, I.; Pena-Muralla, R.; Dickerman, A.; Berg, M.; Rogers, R.; Hutchens, S.; Sweeney, T.C.; McElver, J.; Aux, G.; Patton, D.; et al. Identification of Genes Required for Embryo Development in Arabidopsis. Plant. Physiol. 2004, 135, 1206-1220. [CrossRef]

31. Hirayama, T.; Shinozaki, K. Perception and Transduction of Abscisic Acid Signals: Keys to the Function of the Versatile Plant Hormone ABA. Trends Plant. Sci. 2007, 12, 343-351. [CrossRef] [PubMed]

32. Reverdatto, S.V.; Dutko, J.A.; Chekanova, J.A.; Hamilton, D.A.; Belostotsky, D.A. MRNA Deadenylation by PARN Is Essential for Embryogenesis in Higher Plants. RNA 2004, 10, 1200-1214. [CrossRef]

33. Chiba, Y.; Johnson, M.A.; Lidder, P.; Vogel, J.T.; van Erp, H.; Green, P.J. AtPARN Is an Essential Poly(A) Ribonuclease in Arabidopsis. Gene 2004, 328, 95-102. [CrossRef] [PubMed]

34. Nishimura, N.; Kitahata, N.; Seki, M.; Narusaka, Y.; Narusaka, M.; Kuromori, T.; Asami, T.; Shinozaki, K.; Hirayama, T. Analysis of ABA Hypersensitive Germination2 Revealed the Pivotal Functions of PARN in Stress Response in Arabidopsis. Plant J. 2005, 44, 972-984. [CrossRef] [PubMed]

35. Otsuka, K.; Mamiya, A.; Konishi, M.; Nozaki, M.; Kinoshita, A.; Tamaki, H.; Arita, M.; Saito, M.; Yamamoto, K.; Hachiya, T.; et al. Temperature-Dependent Fasciation Mutants Provide a Link between Mitochondrial RNA Processing and Lateral Root Morphogenesis. eLife 2021, 10, e61611. [CrossRef] [PubMed] 
36. Kanazawa, M.; Ikeda, Y.; Nishihama, R.; Yamaoka, S.; Lee, N.-H.; Yamato, K.T.; Kohchi, T.; Hirayama, T. Regulation of the Poly(A) Status of Mitochondrial MRNA by Poly(A)-Specific Ribonuclease Is Conserved among Land Plants. Plant. Cell Physiol. 2020, 61, 470-480. [CrossRef] [PubMed]

37. Gagliardi, D.; Kuhn, J.; Spadinger, U.; Brennicke, A.; Leaver, C.J.; Binder, S. An RNA Helicase (AtSUV3) Is Present in Arabidopsis thaliana Mitochondria. FEBS Lett. 1999, 458, 337-342. [CrossRef]

38. Tuteja, N.; Sahoo, R.K.; Garg, B.; Tuteja, R. OsSUV3 Dual Helicase Functions in Salinity Stress Tolerance by Maintaining Photosynthesis and Antioxidant Machinery in Rice (Oryza sativa L. Cv. IR64). Plant. J. 2013, 76, 115-127. [CrossRef]

39. Pagnussat, G.C.; Yu, H.-J.; Ngo, Q.A.; Rajani, S.; Mayalagu, S.; Johnson, C.S.; Capron, A.; Xie, L.-F.; Ye, D.; Sundaresan, V. Genetic and Molecular Identification of Genes Required for Female Gametophyte Development and Function in Arabidopsis. Development 2005, 132, 603-614. [CrossRef]

40. Parker, R.; Song, H. The Enzymes and Control of Eukaryotic MRNA Turnover. Nat. Struct. Mol. Biol. 2004, 11, 121-127. [CrossRef]

41. Houseley, J.; LaCava, J.; Tollervey, D. RNA-Quality Control by the Exosome. Nat. Rev. Mol. Cell Biol. 2006, 7, 529-539. [CrossRef]

42. Garneau, N.L.; Wilusz, J.; Wilusz, C.J. The Highways and Byways of MRNA Decay. Nat. Rev. Mol. Cell Biol. 2007, 8, 113-126. [CrossRef]

43. Houseley, J.; Tollervey, D. The Many Pathways of RNA Degradation. Cell 2009, 136, 763-776. [CrossRef] [PubMed]

44. Condon, C. Maturation and Degradation of RNA in Bacteria. Curr. Opin. Microbiol. 2007, 10, 271-278. [CrossRef] [PubMed]

45. Belasco, J.G. All Things Must Pass: Contrasts and Commonalities in Eukaryotic and Bacterial MRNA Decay. Nat. Rev. Mol. Cell Biol. 2010, 11, 467-478. [CrossRef]

46. Gagliardi, D.; Stepien, P.P.; Temperley, R.J.; Lightowlers, R.N.; Chrzanowska-Lightowlers, Z.M.A. Messenger RNA Stability in Mitochondria: Different Means to an End. Trends Genet. 2004, 20, 260-267. [CrossRef]

47. Hammani, K.; Giegé, P. RNA Metabolism in Plant Mitochondria. Trends Plant. Sci. 2014, 19, 380-389. [CrossRef] [PubMed]

48. D'Souza, A.R.; Minczuk, M. Mitochondrial Transcription and Translation: Overview. Essays Biochem. 2018, 62, 309-320. [CrossRef]

49. Anderson, S.; Bankier, A.T.; Barrell, B.G.; de Bruijn, M.H.L.; Coulson, A.R.; Drouin, J.; Eperon, I.C.; Nierlich, D.P.; Roe, B.A.; Sanger, F.; et al. Sequence and Organization of the Human Mitochondrial Genome. Nature 1981, 290, 457-465. [CrossRef]

50. Nagaike, T.; Suzuki, T.; Ueda, T. Polyadenylation in Mammalian Mitochondria: Insights from Recent Studies. Biochim. Biophys. Acta BBA-Gene Regul. Mech. 2008, 1779, 266-269. [CrossRef]

51. Levy, S.; Schuster, G. Polyadenylation and Degradation of RNA in the Mitochondria. Biochem. Soc. Trans. 2016, 44, 1475-1482. [CrossRef]

52. Tomecki, R.; Dmochowska, A.; Gewartowski, K.; Dziembowski, A.; Stepien, P.P. Identification of a Novel Human Nuclear-Encoded Mitochondrial Poly(A) Polymerase. Nucl. Acids Res. 2004, 32, 6001-6014. [CrossRef]

53. Piechota, J.; Tomecki, R.; Gewartowski, K.; Szczesny, R.; Dmochowska, A.; Kudła, M.; Dybczyńska, L.; Stepien, P.P.; Bartnik, E. Differential Stability of Mitochondrial MRNA in HeLa Cells. Acta Biochim. Pol. 2006, 53, 157-167. [CrossRef]

54. Slomovic, S.; Laufer, D.; Geiger, D.; Schuster, G. Polyadenylation and Degradation of Human Mitochondrial RNA: The Prokaryotic Past Leaves Its Mark. Mol. Cell Biol. 2005, 25, 6427-6435. [CrossRef]

55. Toompuu, M.; Tuomela, T.; Laine, P.; Paulin, L.; Dufour, E.; Jacobs, H.T. Polyadenylation and Degradation of Structurally Abnormal Mitochondrial TRNAs in Human Cells. Nucleic Acids Res. 2018, 46, 5209-5226. [CrossRef] [PubMed]

56. Osinga, K.A.; De Vrries, E.; Van der Horst, G.; Tabak, H.F. Processing of Yeast Mitochondrial Messenger RNAs at a Conserved Dodecamer Sequence. EMBO J. 1984, 3, 829-834. [CrossRef] [PubMed]

57. Butow, R.A.; Zhu, H.; Perlman, P.; Conrad-Webb, H. The Role of a Conserved Dodecamer Sequence in Yeast Mitochondrial Gene Expression. Genome 1989, 31, 757-760. [CrossRef] [PubMed]

58. Li, H.; Zassenhaus, H.P. Purification and Characterization of an RNA Dodecamer Sequence Binding Protein from Mitochondria of Saccharomyces cerevisiae. Biochem. Biophys. Res. Commun. 1999, 261,740-745. [CrossRef] [PubMed]

59. Holec, S.; Lange, H.; Canaday, J.; Gagliardi, D. Coping with Cryptic and Defective Transcripts in Plant Mitochondria. Biochim. Biophys. Acta BBA—Gene Regul. Mech. 2008, 1779, 566-573. [CrossRef] [PubMed]

60. Nagaike, T.; Suzuki, T.; Katoh, T.; Ueda, T. Human Mitochondrial MRNAs Are Stabilized with Polyadenylation Regulated by Mitochondria-Specific Poly(A) Polymerase and Polynucleotide Phosphorylase. J. Biol. Chem. 2005, 280, 19721-19727. [CrossRef]

61. Khemici, V.; Linder, P. RNA Helicases in RNA Decay. Biochem. Soc. Trans. 2018, 46, 163-172. [CrossRef]

62. Borowski, L.S.; Dziembowski, A.; Hejnowicz, M.S.; Stepien, P.P.; Szczesny, R.J. Human Mitochondrial RNA Decay Mediated by PNPase-HSuv3 Complex Takes Place in Distinct Foci. Nucleic Acids Res. 2013, 41, 1223-1240. [CrossRef]

63. Wang, D.D.-H.; Guo, X.E.; Modrek, A.S.; Chen, C.-F.; Chen, P.-L.; Lee, W.-H. Helicase SUV3, Polynucleotide Phosphorylase, and Mitochondrial Polyadenylation Polymerase Form a Transient Complex to Modulate Mitochondrial MRNA Polyadenylated Tail Lengths in Response to Energetic Changes*. J. Biol. Chem. 2014, 289, 16727-16735. [CrossRef]

64. Chujo, T.; Ohira, T.; Sakaguchi, Y.; Goshima, N.; Nomura, N.; Nagao, A.; Suzuki, T. LRPPRC/SLIRP Suppresses PNPase-Mediated MRNA Decay and Promotes Polyadenylation in Human Mitochondria. Nucleic Acids Res. 2012, 40, 8033-8047. [CrossRef] [PubMed]

65. Schuster, G.; Stern, D. Chapter 10 RNA Polyadenylation and Decay in Mitochondria and Chloroplasts. In Molecular Biology of RNA Processing and Decay in Prokaryotes; Academic Press: Cambridge, MA, USA, 2009; Volume 85, pp. 393-422. ISBN $1877-1173$.

66. Wahle, E.; Winkler, G.S. RNA Decay Machines: Deadenylation by the Ccr4-Not and Pan2-Pan3 Complexes. Biochim. Biophys. Acta BBA-Gene Regul. Mech. 2013, 1829, 561-570. [CrossRef] 
67. Schäfer, I.B.; Yamashita, M.; Schuller, J.M.; Schüssler, S.; Reichelt, P.; Strauss, M.; Conti, E. Molecular Basis for Poly(A) RNP Architecture and Recognition by the Pan2-Pan3 Deadenylase. Cell 2019, 177, 1619-1631.e21. [CrossRef]

68. Aström, J.; Aström, A.; Virtanen, A. In Vitro Deadenylation of Mammalian MRNA by a HeLa Cell 3’ Exonuclease. EMBO J. 1991, 10, 3067-3071. [CrossRef] [PubMed]

69. Korner, C.G.; Wormington, M.; Muckenthaler, M.; Schneider, S.; Dehlin, E.; Wahle, E. The Deadenylating Nuclease (DAN) Is Involved in Poly(A) Tail Removal during the Meiotic Maturation of Xenopus Oocytes. EMBO J. 1998, 17, 5427-5437. [CrossRef]

70. Tourrière, H.; Chebli, K.; Tazi, J. MRNA Degradation Machines in Eukaryotic Cells. Biochimie 2002, 84, 821-837. [CrossRef]

71. Nousch, M.; Techritz, N.; Hampel, D.; Millonigg, S.; Eckmann, C.R. The Ccr4-Not Deadenylase Complex Constitutes the Main Poly(A) Removal Activity in C. Elegans. J. Cell Sci. 2013, 126, 4274-4285. [CrossRef]

72. Stuart, B.D.; Choi, J.; Zaidi, S.; Xing, C.; Holohan, B.; Chen, R.; Choi, M.; Dharwadkar, P.; Torres, F.; Girod, C.E.; et al. Exome Sequencing Links Mutations in PARN and RTEL1 with Familial Pulmonary Fibrosis and Telomere Shortening. Nat. Genet. 2015, 47, 512-517. [CrossRef] [PubMed]

73. Moon, D.H.; Segal, M.; Boyraz, B.; Guinan, E.; Hofmann, I.; Cahan, P.; Tai, A.K.; Agarwal, S. Poly(A)-Specific Ribonuclease (PARN) Mediates 3'-End Maturation of the Telomerase RNA Component. Nat. Genet. 2015, 47, 1482-1488. [CrossRef] [PubMed]

74. Montellese, C.; Montel-Lehry, N.; Henras, A.K.; Kutay, U.; Gleizes, P.-E.; O’Donohue, M.-F. Poly(A)-Specific Ribonuclease Is a Nuclear Ribosome Biogenesis Factor Involved in Human 18S RRNA Maturation. Nucleic Acids Res. 2017, 45, $6822-6836$. [CrossRef] [PubMed]

75. Shukla, S.; Bjerke, G.A.; Muhlrad, D.; Yi, R.; Parker, R. The RNase PARN Controls the Levels of Specific MiRNAs That Contribute to P53 Regulation. Mol. Cell 2019, 73, 1204-1216.e4. [CrossRef]

76. Johnson, J.M.; Thürich, J.; Petutschnig, E.K.; Altschmied, L.; Meichsner, D.; Sherameti, I.; Dindas, J.; Mrozinska, A.; Paetz, C.; Scholz, S.S.; et al. A Poly(A) Ribonuclease Controls the Cellotriose-Based Interaction between Piriformospora Indica and Its Host Arabidopsis. Plant. Physiol. 2018, 176, 2496-2514. [CrossRef]

77. Liang, W.; Li, C.; Liu, F.; Jiang, H.; Li, S.; Sun, J.; Wu, X.; Li, C. The Arabidopsis Homologs of CCR4-Associated Factor 1 Show MRNA Deadenylation Activity and Play a Role in Plant Defence Responses. Cell Res. 2009, 19, 307-316. [CrossRef]

78. Suzuki, Y.; Arae, T.; Green, P.J.; Yamaguchi, J.; Chiba, Y. AtCCR4a and AtCCR4b Are Involved in Determining the Poly(A) Length of Granule-Bound Starch Synthase 1 Transcript and Modulating Sucrose and Starch Metabolism in Arabidopsis thaliana. Plant. Cell Physiol. 2015, 56, 863-874. [CrossRef]

79. Nishimura, N.; Okamoto, M.; Narusaka, M.; Yasuda, M.; Nakashita, H.; Shinozaki, K.; Narusaka, Y.; Hirayama, T. ABA Hypersensitive Germination2-1 Causes the Activation of Both Abscisic Acid and Salicylic Acid Responses in Arabidopsis. Plant. Cell Physiol. 2009, 50, 2112-2122. [CrossRef]

80. Hirayama, T.; Matsuura, T.; Ushiyama, S.; Narusaka, M.; Kurihara, Y.; Yasuda, M.; Ohtani, M.; Seki, M.; Demura, T.; Nakashita, H.; et al. A Poly(A)-Specific Ribonuclease Directly Regulates the Poly(A) Status of Mitochondrial MRNA in Arabidopsis. Nat. Commun. 2013, 4, 2247. [CrossRef]

81. Waltz, F.; Nguyen, T.-T.; Arrivé, M.; Bochler, A.; Chicher, J.; Hammann, P.; Kuhn, L.; Quadrado, M.; Mireau, H.; Hashem, Y.; et al. Small Is Big in Arabidopsis Mitochondrial Ribosome. Nat. Plants 2019, 5, 106. [CrossRef]

82. Hirayama, T. A Unique System for Regulating Mitochondrial MRNA Poly(A) Status and Stability in Plants. Plant. Signal. Behav. 2014, 9, e973809. [CrossRef] [PubMed]

83. Bowman, J.L.; Floyd, S.K.; Sakakibara, K. Green Genes-Comparative Genomics of the Green Branch of Life. Cell 2007, 129, 229-234. [CrossRef]

84. Sugiyama, M. Isolation and Initial Characterization of Temperature-Sensitive Mutants of Arabidopsis thaliana That Are Impaired in Root Redifferentiation. Plant. Cell Physiol. 2003, 44, 588-596. [CrossRef] [PubMed]

85. MacIntosh, G.C.; Castandet, B. Organellar and Secretory Ribonucleases: Major Players in Plant RNA Homeostasis. Plant. Physiol. 2020, 183, 1438-1452. [CrossRef] [PubMed]

86. Zimorski, V.; Ku, C.; Martin, W.F.; Gould, S.B. Endosymbiotic Theory for Organelle Origins. Curr. Opin. Microbiol. 2014, $22,38-48$. [CrossRef] [PubMed]

87. Roger, A.J.; Muñoz-Gómez, S.A.; Kamikawa, R. The Origin and Diversification of Mitochondria. Curr. Biol. 2017, 27 , R1177-R1192. [CrossRef]

88. Salinas-Giegé, T.; Cavaiuolo, M.; Cognat, V.; Ubrig, E.; Remacle, C.; Duchêne, A.-M.; Vallon, O.; Maréchal-Drouard, L. Polycytidylation of Mitochondrial MRNAs in Chlamydomonas Reinhardtii. Nucleic Acids Res. 2017, 45, 12963-12973. [CrossRef] 